\title{
Short-term outcomes of transanal haemorrhoidal dearterialization versus tissue-selecting technique
}

\author{
Y. Bashir $^{1} \cdot$ Q. Ulain ${ }^{1} \cdot$ E. Eguare $^{1}$ \\ Received: 4 January 2018 / Accepted: 5 January 2018 / Published online: 16 January 2018 \\ ๑) Springer International Publishing AG, part of Springer Nature 2018
}

\section{Dear Sir,}

A recent randomized controlled trial (RCT) published in your journal by Leung et al. evaluating the short-term outcomes of transanal haemorrhoidal dearterialization versus tissue-selecting technique (TST) [1] attracted our attention as the results were different from those reported in the literature: Outcomes after THD were significantly worse than after tissue-selecting technique.

We also read the correspondence by Ratto et al. [2] who highlighted some serious weaknesses in the trial, especially that the CONSORT protocol was not followed by the authors, the trial was not registered, leading to inability to check the predetermined endpoints, and the sample size was calculated using a pain score as a standard and endpoint instead of intention to treat.

We would like to draw your attention to a very important question regarding this trial, which needs urgent attention. In 2014, an article was published in your journal by the same group of surgeons [3]. It compared THD with stapled haemorrhoidectomy, and looking back at the results we see that a $10.26 \%$ (3) recurrence rate was reported after THD performed on 40 patients. In the study on THD versus TST, the recurrence rate after THD was $42.5 \%$ [1]. Moreover, $42.5 \%$ recurrence after THD does not agree with any previously reported recurrence rates for THD. A systematic review done by Sajid et al. [4] showed recurrence rates ranging from $10 \%$ [5] to $21 \%$ [6] in multiple RCTs, while in our own experience with 324 patients the recurrence rate after THD was $16 \%$ [7].

In our opinion, all these questions need to be answered by the authors to clarify these discrepancies and ensure the integrity of their data.

\section{Y. Bashir}

yasirb1@outlook.com

1 Department of General Surgery, Trinity College Dublin, Dublin, Kildare, Ireland

\section{Compliance with ethical standards}

Conflict of interest The authors declare that they have no conflict of interest.

Ethical approval This article does not contain any studies with human participants performed by any of the authors.

Informed consent For this type of study, formal consent is not required.

\section{References}

1. Leung A, Cheung T, Tung $\mathrm{K}$ et al (2017) A prospective randomized controlled trial evaluating the short-term outcomes of transanal hemorrhoidal dearterialization versus tissue-selecting technique. Tech Coloproctol 21(9):737-743

2. Biondo S, Trenti L, Kreisler E, Ratto C (2017) A prospective randomized trial on transanal hemorrhoidal dearterialization versus stapler hemorrhoidectomy: methodological issues that need to be clarified. Tech Coloproctol. https://doi.org/10.1007/s10151-0171703-Z

3. Tsang Y, Fok K, Cheung Y, Li K, Tang C (2014) Comparison of transanal haemorrhoidal dearterialisation and stapled haemorrhoidopexy in management of haemorrhoidal disease: a retrospective study and literature review. Tech Coloproctol 18(11):1017-1022

4. Sajid M, Parampalli U, Whitehouse P, Sains P, McFall M, Baig M (2012) A systematic review comparing transanal haemorrhoidal de-arterialisation to stapled haemorrhoidopexy in the management of haemorrhoidal disease. Tech Coloproctol 16(1):1-8

5. Giordano P, Nastro P, Davies A, Gravante G (2011) Prospective evaluation of stapled haemorrhoidopexy versus transanal haemorrhoidal dearterialisation for stage II and III haemorrhoids: 3-year outcomes. Tech Coloproctol 15(1):67-73

6. Festen S, Van Hoogstraten M, Van Geloven A, Gerhards M (2009) Treatment of grade III and IV haemorrhoidal disease with PPH or THD. A randomized trial on postoperative complications and short-term results. Int J Colorectal Dis 24(12):1401

7. Ain QU, Bashir Y, Eguare E (2017) Evaluation of the effectiveness and patients' contentment with transanal haemorrhoidal artery dearterialisation and mucopexy (THD) for treatment of haemorrhoidal disease: a 6-year study. Ir J Med Sci. https://doi. org/10.1007/s11845-017-1715-8 